\title{
Coping with the Burden of Eye-Care Delivery
}

\author{
Augustine U Akujobi* \\ Augustine U Akujobi, Department of Optometry, Imo State University, Owerri, Nigeria
}

*Corresponding author: Augustine U Akujobi, Department of Optometry, Imo State University, Owerri, Nigeri.

Received Date: November 11, 2018

Published Date: December 05, 2018

\section{Short Communication}

In recent times, ocular and visual anomalies have grown significantly among various populations of the world. In many parts of the globe, the number of persons who attain old age has increased as a result of improved medical technology and health education. The soaring number of the aged population has inadvertently, contributed in no small measure, to the alarming prevalence of oculo-visual anomalies [1,2]. Apart from its direct implication in the aetiology of oculo-visual disorders, age remains a considerable factor in the causation of certain systemic diseases, such as hypertension and diabetes, which have been shown to exhibit significant ocular effects [3]. Moreover, other debilitating ocular anomalies, such as cataract, glaucoma, age-related macular degeneration [ARMD] and corneal opacity have also been associated with older ages [4].

In addition, the application of various electronic and computer devices in vocational and social task performances places an undue demand and stress on the oculo-visual system. Consequently, the prevalence of computer vision syndrome [CVS] or digital eyestrain [DES] has escalated, in some cases to $72 \%$ [5], 67.4\% [6], 50\% [7] and 54.6\% [8] in many other instances, while Dessie, Adane, Nega, Wami \& Chercas [9] have recently put the figure at $69.5 \%$. School enrolments have improved in both the developed and developing nations, probably as a result of the sustained advocacy for child education by various local and international agencies. Even among the developing and under-developed countries, makeshift educational resources are provided for displaced persons in refugee camps to ensure their continued stay within educational facilities. The more the number of school enrolments, the more the children that need functional vision for academic purposes, therefore, regular school eye health programmers are needful for early detection and management of oculo-visual anomalies and the referral of ancillary cases.

Furthermore, environmental pollution has become an ocular health concern. As more cities and suburbs undergo construction works, the environment suffers degradation and produces more pollutants. More gases and particulate matters from machines and automobiles are released into the environment with attendant consequences on the ocular surface. With increased environmental antigenic stimulation, persons with allergic and atopic tendencies may suffer from compromised mucosal immune response which ultimately leads to impaired quality of life. Affected people may complain of irritation, redness, foreign body sensation, tearing, and blurring of vision [10]. On the overall, the number of people plagued by various forms of oculo-visual anomalies is increasing by the day. The burden imposed by these statistics on the eyecare team is enormous. More than ever before, the optometrists, ophthalmologists and opticians are confronted with emerging and re-emerging anomalies that require novel techniques, hence, the need to acquire and update requisite knowledge and clinical skills, as well as, procure more sophisticated equipment to meet the evolving eye-care needs of the teaming patient load.

More importantly, inter-professional referrals and collaborations should be advocated and practiced to enhance the quality of service delivery within the eye-care team; this will provide the appropriate and correct expertise to satisfy the spectrum of patients' needs. Moreover, the paradigm shift from generalization to specialization in the past few decades lends credence to team work, which is pivotal to effective eye-care delivery. Within the team, each member must recognize and appreciate the expertise and skill of the other, solicit and engage such in patient-care. Although the model of collaboration must not be strictly regimented, the overall mission must be guided by certain basic principles which are patient-centered. Such principles include; timeliness of professional contact, commitment to standard care, evidence-based approach to care, collegial relationships, effective and timely communication, optimal use of professional competence and resources and non-duplication of tests [11]. Therefore, to actualize a comprehensive and quality eye-care delivery, the trio must dismantle all professional barriers, build a strong team, adopt a patient-oriented approach and deploy all pertinent skills and knowledge to the service of the 
patients.

\section{Acknowledgement}

None.

\section{Conflicts of Interest}

No conflicts of interest.

\section{References}

1. Woodruff ME (1977) Prevalence of visual and ocular anomalies in 168 non-institutionalized mentally retarded children. Canadian Journal of Public Health 68(3): 225-232.

2. Nartey ET, Van Staden DB, Amedo AO (2016) Prevalence of ocular anomalies among schoolchildren in Ashaiman, Ghana. Optometry and Vision Science 93(6): 607-611.

3. Wang G, Bia Z, Shi J, Luo S, Chang H, et al. (2013) Prevalence and risk factors for eye diseases, blindness, and low vision in Lhasa, Tibet. International Journal of Ophthalmology 6(2): 237-241.

4. Guo C, Wang Z, He P, Chen G, Zheng X (2017) Prevalence causes and social factors of visual impairment among Chinese adults: based on a national survey. International Journal of Environmental Research and Public Health 14(4): E1034.
5. Al Rashidi SH \& Alhumaidan H (2017) Computer vision syndrome prevalence, knowledge and associated factors among Saudi Arabia University students: Is it a serious problem? International Journal of Health Sciences 11(5): 17-19.

6. Ranasinghe P, Wathurapatha WS, Perera YS, Lamabadusuriya DA, Kulatunga S Jayawardana N, et al. (2016) Computer vision syndrome among computer office workers in a developing country: an evaluation of prevalence and risk factors. BioMed Central Research Notes 9:150.

7. Sheppard AL, Wolffsohn JC (2018) Digital eyestrain: prevalence, measurement and amelioration. BMJ Open Ophthalmology 3(1): e000146.

8. Eduardo S, Rocha L (2014) The prevalence of risk factors associated with computer vision syndrome among computer works in Sao Paulo, Brazil. Occupational and Environmental Medicine 71(1): 297-298.

9. Dessie A, Adane F, Nega A, Wami SD, Chercos DH (2018) Computer vision syndrome and associated factors among computer users in Debre Tabor Town, Northwest Ethiopia. Journal of Environmental and Public Health 1-9.

10. Jung SJ, Mehta JS, Tong L (2018) Effects of environment pollution on the ocular surface. Ocular Surface, 16(2): 198-205.

11. Canadian Glaucoma Society (2011) Model of interprofessional collaboration in the care of glaucoma patients and glaucoma suspects. Canadian Journal of Ophthalmology 46(6suppl): 1-10. 